\title{
Benchmarks
}

(locked nucleic acid). Exp. Rev. Mol. Diagn. 3:7-38.

13.Kurreck, J., E. Wyszko, C. Gillen, and V.A. Erdmann. 2002. Design of antisense oligonucleotides stabilized by locked nucleic acids. Nucleic Acids Res. 30:1911-1918.

14.Petersen, M. and J. Wengel. 2003. LNA: a versatile tool for therapeutics and genomics. Trends Biotechnol. 21:74-81.

15.Simeonov, A. and T.T. Nikiforov. 2002. Single nucleotide polymorphism genotyping using short, fluorescently labelled locked nucleic acid (LNA) probes and fluorescence polarization detection. Nucleic Acids Res. 30:e91.

16.Orum, H., M.H. Jakobsen, T. Koch, J. Vuust, and M.B. Borre. 1999. Detection of the factor V Leiden mutation by direct allele-specific hybridization of PCR amplicons to photoimmobilized locked nucleic acids. Clin. Chem. 45:1898-1905.

17.Latorra, D., K. Campbell, A. Wolter, and J.M. Hurley. Enhanced allele specific PCR discrimination in SNP genotyping using 3 locked nucleic acid (LNA) primers. Hum. Mutat. (In Press.)

18.Christensen, U., N. Jacobsen, V.K. Rajwanshi, J. Wengel, and T. Koch. 2001. Stoppedflow kinetics of locked nucleic acid (LNA) oligonucleotide duplex formation: studies of LNA-DNA and DNA-DNA interactions. Biochem. J. 354:481-484.

Address correspondence to Dr. David Latorra, Proligo LLC, 6200 Lookout Road, Boulder, CO 80301, USA. e-mail: dlatorra@proligo.com

Received 27 February 2003; accepted 31 March 2003.

David Latorra, Deborah Hopkins, Krista Campbell, and J. Michael Hurley

Proligo LLC

Boulder, CO, USA

\section{Encapsulation of Acetylcholinesterase in Preformed Liposomes}

BioTechniques 34:1158-1162 (June 2003)

Acetylcholinesterase (AChE) is highly sensitive to pesticides and has been engineered to become a real tool for their detection (1). However, its utilization in biosensors faces a major problem. The enzyme is not stable enough to be useful for pesticide detection in the field. One way to increase an enzyme's stability is to encapsulate it in liposomes or nanocapsules $(2,3)$. This encapsulation stabilizes the enzyme against dilution effects and protects it against proteolytic agents. In the following experiments, we encapsulated $\mathrm{AChE}$ in liposomes. For encapsulation, we tried different established techniques. The first one forms the capsule from lipids in the presence of protein. The technique consists of mixing a protein-containing aqueous solution with a lipid solution solubilized either by a detergent or by an organic solvent. By removing either the detergent by dialysis (4) or the organic solvent by evaporation [the reverse-phase evaporation method (5)], the lipids organize in bilayers around aqueous droplets of enzyme solution and form liposomes. However, these techniques are highly damaging for fragile proteins that are denatured by detergents, solubilized lipids, or organic solvents. When we tested the detergent dialysis technique, we noticed that $50 \%$ of AChE involved in this process was denatured; $70 \%$ was denatured by the reverse-phase evaporation method (data not shown). An alternative technique consists of adding the protein to a preformed dry lipid film. The dispersion of the dry lipid film with a protein-containing aqueous solution leads to the formation of multilamellar vesicles. They are converted to monolamellar vesicles by repeated freeze-thaw cycles or by sonication $(6,7)$. During sonication, however, the intact membrane is lysed. These membrane fragments seem to behave like a detergent and denature the AChE up to $90 \%$ after $1 \mathrm{~min}$ of sonication (data not shown). Therefore, the most suitable 


\section{Benchmarks}

technique of encapsulation of fragile enzymes such as AChE would appear to be the hydration of a dry lipid film followed by several freeze-thaw cycles.

Current opinion holds that encapsulation occurs with the liposome formation during hydration of the lipid (3). However, it appears that only negligible amounts of protein, corresponding to $1 \%-2 \%$ of the starting enzyme quantity, are encapsulated during the film hydration (3) (data not shown). Thus, our preliminary experiments strongly suggested that encapsulation does not occur during the vesicle budding-off, but proteins are loaded in liposomes during the freeze-thaw cycles initially performed to convert multilamellar to unilamellar liposomes. To test this hypothesis, we prepared liposome suspensions without the enzyme simply by vigorously mixing $50 \mathrm{mg}$ egg phosphatidylcholine lipid powder (Lipoïd, Ludwigshafen, Germany) with $1 \mathrm{~mL}$ 25 mM MOPS (Sigma, St. Louis, MO, USA), pH 7.4, buffer using a vortex mixer. One hundred microliters of this suspension were added in a $5-\mathrm{mL}$ glass tube. The solution was then subjected to 10 freeze-thaw cycles to obtain monolamellar vesicles. The tube was successively dipped in a liquid nitrogen bath $\left(-195^{\circ} \mathrm{C}\right)$ and a water bath $\left(37^{\circ} \mathrm{C}\right)$. Then, $100 \mu \mathrm{L} 25 \mathrm{mM}$ MOPS, pH 7.4,

Table 1. Comparison of AChE Denaturation Using Different Encapsulation Strategies

\begin{tabular}{|lcc|}
\hline Encapsulation Method & $\begin{array}{c}\text { Reference(s) } \\
\text { for Procedure }\end{array}$ & \% Denaturation \\
\hline Detergent dialysis & 3 and 4 & 50 \\
Reverse-phase evaporation & 3 and 5 & 70 \\
Lipid film hydration and sonication & 3,6, and 7 & 90 \\
Freeze-thaw of preformed liposomes & (This study) & $\sim 10$ \\
\hline
\end{tabular}

buffer containing $0.3 \mathrm{nmol} \mathrm{AChE}$ were added in the tube to the liposome suspension. To test the effect of the freeze-thawing on the encapsulation efficiency, mixtures of monolamellar liposomes and the AChE solution underwent a defined number of freezethaw cycles. Next, the sample was diluted to $1 \mathrm{~mL}$ in $25 \mathrm{mM}$ MOPS, $\mathrm{pH} 7.4$, buffer. Particles of homogenous size were obtained by extrusion by passing the sample 10 times through a $200-\mathrm{nm}$ pore filter (Schleicher \& Schuell, Dassel, Germany). Liposome size was estimated by dynamic light scattering to be $200 \mathrm{~nm}$ in diameter. The non-encapsulated enzymes were removed by adding $1 \mathrm{mg} / \mathrm{mL}$ protease and incubating for 3 $\mathrm{h}$ at room temperature with the liposome suspension after extrusion. The amount of encapsulated enzyme was then measured by recording the en- zyme activity in the presence of $0.1 \%$ Triton ${ }^{\circledR}$ X-100 (Sigma) to dissolve the liposomes. To measure the denaturing effect of the encapsulation process on $\mathrm{AChE}$, the enzyme activity was measured in presence of $0.1 \%$ Triton X-100 before the addition of $1 \mathrm{mg} / \mathrm{mL}$ protease (Pronase; Sigma). In all cases, AChE activity was measured using the sensitive Ellman's method (8) with 1 $\mathrm{mM}$ acetylthiocholine (Sigma). AChE catalyzes the hydrolysis of acetylthiocholine, producing acetate and thiocholine; thiocholine is then able to react with dithionitrobenzoic acid (Sigma) contained in the Ellman reagent, producing a compound that is detectable by A measurements at $412 \mathrm{~nm}$ with an $\varepsilon=13,600 \mathrm{M} / \mathrm{cm}$. AChE's activity is equal to the absorbance variation plotted versus time.

Figure 1 clearly demonstrates that

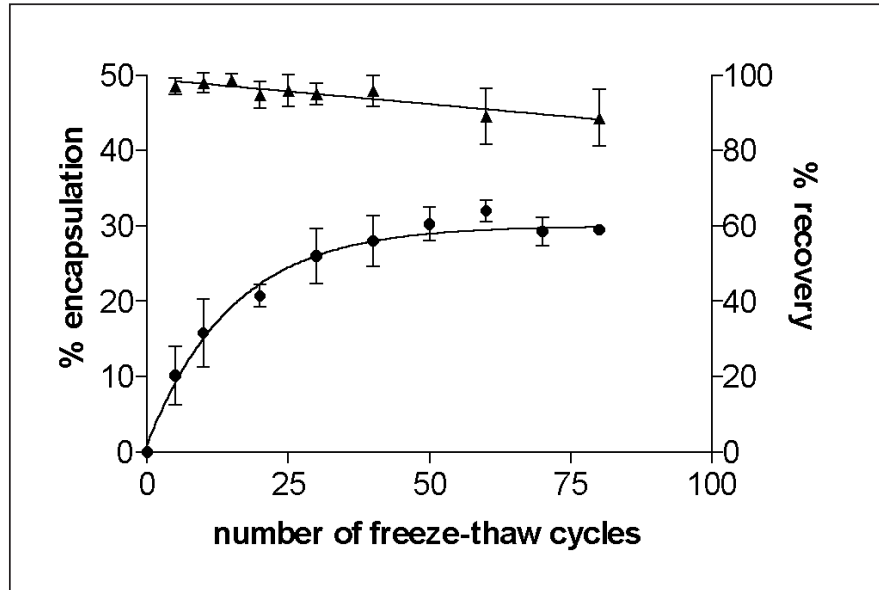

Figure 1. Encapsulation of $\mathrm{AChE}$ into liposomes versus the number of freeze-thaw cycles and relative denaturation of $\mathbf{A C h E}$. On the left axis, shows the increase of encapsulation efficiency according to freeze-thaw cycles. Before any freeze-thaw cycles, all AChE is outside the liposomes. Freeze-thaw cycles allow the diffusion of the enzyme into the liposomes and increase the encapsulation efficiency of the process. Equilibrium is reached after the outside concentration equals the concentration of the encapsulated enzyme. On the right axis, $\boldsymbol{\Delta}$ shows the corresponding recovery of AChE according to freeze-thaw cycles. Error bars represent the standard deviation.

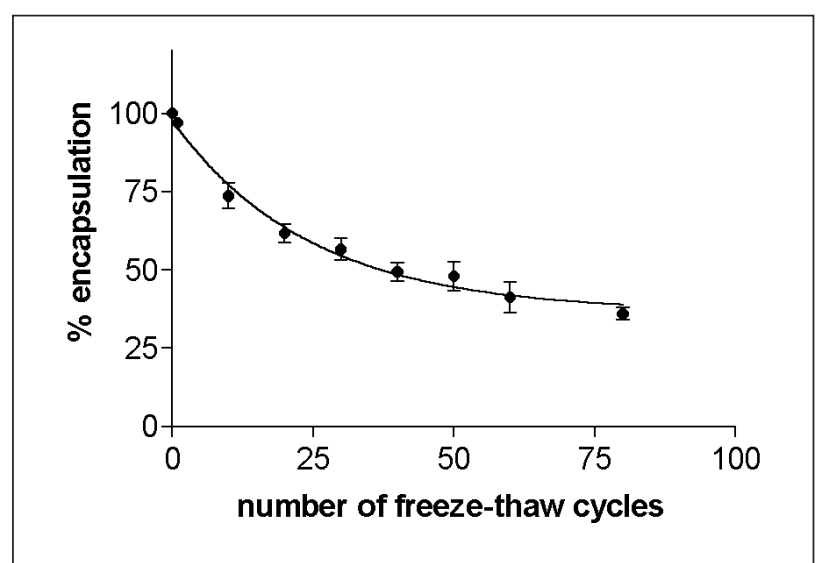

Figure 2. Leakage of the encapsulated $\mathrm{AChE}$ versus the number of freeze-thaw cycles. Before any freeze-thaw cycle, the outer solution contains no AChE. Liposomes have been previously loaded with AChE. shows the exit of AChE from the liposomes according to freeze-thaw cycles. Freeze-thaw cycles allow the diffusion of the enzyme from inside the liposomes to the outer solution, and then the percentage of encapsulated AChE decreases. 


\section{Benchmarks}

encapsulation occurs during the freezethaw cycles and that its efficiency increases with the increase of the number of cycles. The plateau reached after 50 cycles represents maximum encapsulation efficiency and corresponds to the calculated volume ratio of inner volume out of the total volume. In other words, the inside protein concentration is now equal to the outside one. In the experiment shown in Figure 1, the inner volume corresponded to $30 \%$ of the total volume; after 50 freeze-thaw cycles, $30 \%$ of the proteins were encapsulated.

The upper curve in Figure 1 shows the very low denaturing effect of the freeze-thaw cycles on AChE (below $10 \%)$. This low denaturation of AChE during the encapsulation process is a real advantage compared to previously described encapsulation techniques (see Table 1). Repetitive freeze-thaw cycles are usually detrimental to proteins. During thermal changes, buffer acid or basic species have different precipitation behavior in solution, locally creating dramatic $\mathrm{pH}$ changes that denature proteins (9). Fast freezing in liquid nitrogen $\left(-195^{\circ} \mathrm{C}\right)$ and thawing in a water bath $\left(37^{\circ} \mathrm{C}\right)$ avoided this differential precipitation and preserved the protein during the encapsulation procedure. Furthermore, a high concentration of the enzyme to be encapsulated and a high concentration of liposomes protect the protein from denaturation by freezing.

How do enzymes enter into liposomes during the freeze-thaw cycles? At the freezing point, the encapsulated water increases its volume by $10 \%$, leading to a burst in the lipid shell. It is tempting to hypothesize that during the first thawing, the enzymes enter into the liposome through the unclosed fracture. The concentrations of enzymes inside and outside do not equilibrate within a single freeze-thaw cycle, either because the closing of the membrane is too rapid during the thawing or because the probability of opening a large enough fracture during the freezing is low. Maximum of encapsulation efficiency is reached only after the enzyme concentrations are in equilibrium inside and outside of the liposomes. The inner membrane surface of a 200 $\mathrm{nm}$ diameter liposome is $121.000 \mathrm{~nm}^{2}$. The volume increase by water freezing requires an additional $6 \%$ (or 7500 $\mathrm{nm}^{2}$ ) in lipid area, which is beyond the critical area, leading to rupture. In the rigid frozen membrane of the liposome, this surface increase generates at least one fracture among the lipids. This fracture's area corresponds to more than 100 times the surface hindrance of the enzyme $\left(70 \mathrm{~nm}^{2}\right)$. To test this explanation, we forced the enzyme out of the liposomes. Figure 2 shows the effect of the freeze-thaw cycles on the unloading of enzyme-loaded liposomes in a solution free of enzymes. In this case, the concentration gradient causes the diffusion of the enzyme outside the liposomes.

Most of the promising enzymes for the construction of new nanoscaled tools are fragile and do not support harsh conditions. Their encapsulation in liposomes using dialysis, reversephase evaporation, or sonication may denature them. Here, the freeze-thaw of preformed liposomes appears to be an efficient technique to achieve the encapsulation of fragile enzymes.

\section{REFERENCES}

1.Boublik, Y., P. Saint-Aguet, A. Lougarre, M. Arnaud, F. Villatte, S. Estrada-Mondaca, and D. Fournier. 2002. Acetylcholinesterase engineering for detection of insecticide residues. Protein Eng. 15:43-50.

2.Nasseau, M., Y. Boublik, W. Meier, M. Winterhalter, and D. Fournier. 2001. Substrate-permeable encapsulation of enzymes maintains effective activity, stabilizes against denaturation, and protects against proteolytic degradation. Biotechnol. Bioeng. 75:615618

3.Walde, P. and S. Ichikawa. 2001. Enzymes inside lipid vesicles: preparation, reactivity and applications. Biomol. Eng. 18:143-177.

4.Milsmann, M.H., R.A. Schwendener, and H.G. Weder. 1978. The preparation of large single bilayer liposomes by a fast and controlled dialysis. Biochim. Biophys. Acta 512:147-155.

5.Szoka, F., Jr. and D. Papahadjopoulos. 1978. Procedure for preparation of liposomes with large internal aqueous space and high capture by reverse-phase evaporation. Proc. Natl. Acad. Sci. USA 75:4194-4198.

6.Anselem, S., A. Gabizon, Y. Barenholz, and G. Gregoriadis. 1993. Liposome Technology. CRC Press, Boca Raton, FL.

7.Lichtenberg, D. and Y. Barenholz. 1988. Liposomes: preparation, characterization, and preservation. Methods Biochem. Anal. 33:337-462.

8.Ellman, G.L., K.D. Courtney, K.D. Andres, and R.M. Featherstone. 1961. A new and rapid calorimetric determination of acetyl- cholinesterase activity. Biochem. Pharmacol. 7:88-95.

9.Pikal-Cleland, K.A., N. Rodriguez-Hornedo, G.L. Amidon, and J.F. Carpenter. 2000. Protein denaturation during freezing and thawing in phosphate buffer systems: monomeric and tetrameric beta-galactosidase. Arch. Biochem. Biophys. 384:398-406.

Address correspondence to Dr. Didier Fournier, Groupe de Biophysique et de Biotechnologie des Protéines, IPBS-UMR 5089, 205 Route de Narbonne, F-31077 Toulouse, France.e-mail:fournier@ipbs.fr

Received 22 January 2003; accepted 13 March 2003.

\section{Barnabé Chaize, Mathias Winterhalter, and Didier Fournier \\ Institut de Pharmacologie \\ et de Biologie Structurale- \\ Unite Mixte de Recherche \\ 5089}

Toulouse, France

\section{Strategy to Screen Long DNA Inserts in Escherichia coli}

BioTechniques 34:1162-1166 (June 2003)

Propagating DNA fragments in plasmids is a routine procedure in molecular cloning because of its simplicity and efficiency. Commonly used cloning plasmid vectors, such as the $\mathrm{pUC}^{\circledR}$ and $\mathrm{pGEM}^{\circledR}$ series (Promega, Madison, WI, USA), are effective for cloning restricted fragments shorter than $10 \mathrm{~kb}(1)$. However, the probability of cloning of fragments longer than $10 \mathrm{~kb}$ in these vectors is low, and screening clones with long inserts is laborious and time-consuming. For example, when a genomic library of 150-200 kb DNA (e.g., certain viral DNA and BAC clones) is needed, the common approach is to digest the DNA with a restriction endonuclease and lig- 